\title{
Impacto do Controle da Corrupção sobre a Eficiência do Governo no Ano de 2015 O Caso dos Países da América Latina
}

\author{
http://dx.doi.org/10.21527/2237-6453.2019.49.10-29
}

Recebido em: $31 / 8 / 2018$

Aceito em: $11 / 6 / 2019$

\author{
Emanoel de Souza Barros ${ }^{1}$, Gabriel Britto Feitoza ${ }^{2}$
}

\begin{abstract}
RESUMO
Este trabalho visa a analisar o impacto do controle da corrupção sobre a eficiência governamental de 33 países da América Latina e Caribe. Os dados foram obtidos da plataforma web do Banco Mundial com referência ao ano de 2015. Além de uma vasta análise descritiva, este artigo acrescentou duas regressões, uma OLS e uma Tobit, a fim de confirmar os efeitos do controle da corrupção sobre a eficiência governamental dos países analisados. Os resultados mostraram que o quadro da corrupção é endêmico e generalizado na América Latina e Caribe. Os modelos de regressão foram estimados a partir do escore de eficiência governamental como função de seis variáveis explicativas (controle de corrupção, gastos públicos com saúde, contrações econômicas, IPC-2010-2015, consumo do governo e administração pública em relação aos gastos do governo). Os resultados confirmaram a relação positiva existente entre o controle de corrupção e a eficiência do governo, e apontam o controle de corrupção como principal causa da (in)eficiência dos Estados analisados.
\end{abstract}

Palavras-chave: Controle de corrupção. Eficiência do governo. América Latina.

\section{IMPACTS OF CORRUPTION TO GOVERNMENTAL EFFICIENCY IN 2015: CASE TO LATIN AMERICA COUNTRIES}

\section{ABSTRACT}

This paper seeks analyzing the impact of control of corruption on governmental efficiency of 33 countries in Latin America and Caribbean. The data were collected from World Bank (web platform) to 2015. Besides to a descriptive analysis, this paper added two regressions, one OLS and one Tobit, to confirm the effects of corruption control on government efficiency of the countries analyzed. Results show that the corruption framework is endemic in Latin America and Caribbean. Regressions models was estimated considering governmental efficiency score as a function of six explanatory variables (control of corruption, public spending with health, economic contractions, CPI-2010-2015, governmental consumption and public administration in government spending). Results confirm that there are positive relationship between control of corruption and governmental efficiency and identifying the control of corruption like cause of governmental (in)efficiency.

Keywords: Control of corruption. Governmental efficiency. Latin America.

\footnotetext{
${ }^{1}$ Doutor em Economia pela Université Paris 1 - Pantheon Sorbonne, França. Professor da Universidade Federal de Pernambuco (Ufpe). leonamebr@gmail.com

${ }^{2}$ Graduado em Economia pela Universidade Federal de Pernambuco (UFPE). brittogabriel93@gmail.com
} 
Sabe-se que a corrupção será sempre associada a um prejuízo para algum indivíduo ou até mesmo para muitos. Esse fenômeno pode ser bem-representado como um determinado bem ou recurso, que é destinado, originalmente, para uma determinada finalidade ou indivíduo(s), o qual é desviado para outra finalidade ou indivíduo que não deveria $(m)$ estar sendo contemplado(s) com tal bem ou recurso.

O conceito de corrupção possui diversas interpretações. Segundo Bustos (2010 apud Santano, 2015), a corrupção política é uma prática executada por indivíduos empregados em cargo público. Para que haja a prática da corrupção, deve surgir o interesse pessoal do gestor público em desviar os recursos para benefício próprio ou de terceiros em detrimento do restante da sociedade, que deveria ser a beneficiária final.

Segundo Jovatto (2005 apud SANTANO, 2015), a corrupção política pode ser definida como um mau uso e abuso de poder, sendo este público ou privado, com o objetivo de beneficiar partidos políticos, grupos específicos ou mesmo o próprio indivíduo por meio da violação de regras estabelecidas. Dentre os fatores que podem estimular o desenvolvimento de práticas corruptas no âmbito político, tem-se: (i) presença de instituições políticas e econômicas extrativistas (para Acemoglu e Robinson (2012), são instituições que promovem políticas econômicas e sociais que caminham na contramão da inclusão social), (ii) o financiamento de campanhas políticas, e (iii) a participação excessiva dos governos nas economias nacionais. Trabalhos como os de Acemoglu e Robinson (2012), Medieta (2006 apud SANTANO, 2015) e Tanzi (1998 apud CARRARO et al., 2006), enfatizam e analisam cada um desses fatores de forma mais detalhada.

$O$ fato é que a corrupção é um fenômeno de difícil mensuração por se tratar de algo que não é facilmente perceptível. Por isso, os indicadores que avaliam os níveis de corrupção não podem ser considerados altamente exatos. Entre esses indicadores está o Índice de Percepção de Corrupção (PCl) elaborado pela Transparency International (Organização Não Governamental sediada em Berlim, Alemanha, que tem por objetivo o combate à corrupção). Este índice avalia diversos países com notas que variam de zero a cem (quanto mais próximo de cem, menor a percepção de corrupção e maior a noção de transparência associada ao país, e vice-versa) (ABRAMO, 2005).

Ainda segundo Carraro et al. (2006), a corrupção pode afetar negativamente a alocação eficiente dos recursos em geral, gerando ineficiência e queda de produtividade na economia. Menor produtividade representa menor salário. Com o salário comprometido, as famílias podem decidir poupar menos, o que afeta diretamente poupança e nível de investimentos a médio e longo prazos.

Diante dos contextos enunciados anteriormente, o presente estudo justifica-se pelo fato de a corrupção ser um problema grave, mas negligenciado. Sabe-se que práticas corruptas são onerosas para o bem-estar social, mas os dimensionamentos dos impactos negativos sobre a sociedade não são exatos. A corrupção preocupa por ser algo comum na maioria das nações. Em algumas regiões é tão presente que é considerado endêmico e parte integrante da cultura. Tal problema deve ser abordado, neste trabalho, de forma a estabelecer uma associação entre a corrupção e seu ônus social e econômico às sociedades (interpretada como a redução na eficiência do governo). 
Nesse escopo, o presente trabalho pretende realizar um pequeno ensaio tentando associar os níveis endêmicos de corrupção com os impactos negativos sobre a eficiência do governo. Mais especificamente, pretende-se avaliar o impacto do Controle de Corrupção (e outros indicadores) sobre a Eficiência do Governo, para uma amostra de países composta por 33 nações latino-americanas. Como exercício estatístico, serão estimadas, por meio dos métodos OLS e Tobit, regressões com o intuito de verificar (sob essas abordagens) os efeitos da corrupção sobre a eficiência do governo.

Dentre os diversos resultados encontrados pode-se adiantar (de forma preliminar) a realidade de que apenas oito países $(24,24 \%$ da amostra) apresentaram valores para o controle da corrupção superiores a $70 .^{3} \mathrm{~A}$ média do controle da corrupção para a América Latina e Caribe foi de apenas 47,42 , sendo 20 países $(60,6 \%$ da amostra) identificados com controle de corrupção abaixo de 50. Com isso, fica evidente que o descontrole sobre práticas corruptas é endêmico na amostra. A Eficiência do Governo também não é elevada para a média de países da amostra (com média estimada em torno de 47,27). Apenas quatro países $(12,12 \%$ da amostra) obtiveram valores iguais ou superiores a 70 .

A Venezuela e o Haiti foram contabilizados como os países com pior avaliação em controle de corrupção e eficiência do governo. O Brasil, por sua vez, apresentou Controle de Corrupção inferior à média da América Latina e Caribe, com escore fixado em 41. Cerca de 16 nações latino-americanas possuem maior controle sobre práticas corruptas que o apresentado pelo Brasil. Os resultados dados pelas regressões OLS e Tobit mostraram que (dentre as seis variáveis explicativas) apenas o controle da corrupção tem efeito significativo sobre a eficiência dos governos latino-americanos.

Desse modo, para bem-compreender cada um dos pontos enunciados supra, o artigo foi organizado em seis seções, incluindo a presente introdução. A seção Referencial Teórico descreve um breve panorama de estudos econômicos, relacionando o controle de corrupção à eficiência do governo. Na seção Metodologia apresentam-se os seguintes tópicos: i) base de dados; ii) modelo econométrico; e iii) modelo empírico. Os Resultados são apresentados na sequência, e, para finalizar, são expostas as principais Conclusões do trabalho, e, em seguida as Referências bibliográficas empregadas.

\section{REFERENCIAL TEÓRICO}

Dentre os diversos estudos que analisaram a relação entre práticas corruptas e nível de eficiência governamental, pode-se citar os elaborados por Tanzi (1995), Moreira e Teles (2007), Mignozzetti (2012), Lopes e Toyoshima (2013) e Cruz e Ramos (2014).

Partindo da análise desenvolvida por Tanzi (1995), percebe-se que o controle sobre práticas corruptas (feitas por agentes econômicos e funcionários do governo) torna-se um fator determinante para garantir um funcionamento eficiente do governo e dos mercados. Segundo o autor, o governo possui a função normativa de corrigir falhas dos mercados. Quando objetivos alheios à necessidade de corrigir falhas dos mercados predominam, reduz-se a eficiência do governo na regulação dessas falhas. Ou seja, quanto maior for o nível de corrupção dentro do governo menor será o controle do próprio

O controle da corrupção é um indicador que varia de zero (ausência completa de controle sobre práticas corruptas) a cem (controle completo sobre tais práticas). Magnitude similar é aplicada ao índice que retrata a eficiência do governo, sendo o índice zero sinônimo de ausência completa de eficiência e cem sinônimo de eficiência plena. 
governo sobre seus instrumentos de política e, como consequência, menor será sua capacidade em corrigir as imperfeições dos mercados. Como consequência, menor será a eficiência governamental.

Para Moreira e Teles (2007), a corrupção pode ainda ser analisada sob diferentes perspectivas, mas em todas elas ocorre um destaque para o fator confiança pública. As pessoas que possuem uma maior confiança em outros indivíduos tendem a ter uma visão mais otimista em relação às instituições públicas e a participarem de forma mais ativa em organizações cívicas. Esse otimismo também é capaz de afetar positivamente as expectativas em relação ao futuro das pessoas (USLANER, 2002; DELHEY; NEWTON, 2005). Dessa forma, cidades, regiões e até países inteiros podem vislumbrar sociedades mais confiáveis e capazes de possuir instituições públicas e democráticas mais eficientes, espécies de economias mais abertas e estáveis, com maior crescimento e desenvolvimento econômico e com menos práticas corruptas (ZAK; KNACK, 2001).

Baseando-se nos trabalhos de Uslaner (2004) e Eek e Rothstein (2005), a corrupção está associada a baixos níveis de confiança pública. Quando os cidadãos se deparam com uma situação de corrupção praticada por um dado funcionário público, sua confiança na integridade e legitimidade da instituição que o emprega é afetada, o que gera mudanças na percepção em relação à qualidade da instituição pública em questão. Segundo os autores, governos corruptos são, provavelmente, menos eficientes.

Mignozzetti (2012) investiga a questão da qualidade dos governos, sobretudo os democráticos, sob a perspectiva da problemática da corrupção. O autor procura investigar as causas que levariam a corrupção a deteriorar os elementos que determinam o nível de qualidade de um governo e de suas instituições. Para isso, o autor avaliou dados em painel para o período de 1996 a 2005 para 154 países. Os dados foram coletados do banco de dados intitulado Qualidade do Governo (Quality of Government), da Universidade de Gotemburgo, na Suécia.

Os resultados obtidos por Mignozzetti (2011) mostraram que a corrupção afeta direta e negativamente o desempenho dos governos. Um país que apresenta elevados índices de práticas corruptas terá, provavelmente, um desempenho qualitativo do governo bem inferior ao de um país que apresente um controle mais forte sobre a problemática da corrupção. O autor ainda conclui que a corrupção é tão mais grave quanto menos democrático é o país (frisando a necessidade da democracia como essencial ao controle da corrupção).

Inspirados pela preocupação crescente sobre como os governos gastam seus recursos oriundos de impostos, Lopes e Toyoshima (2013) fizeram uma análise da eficiência técnica dos governos estaduais brasileiros na aplicação de recursos públicos destinados às áreas de saúde e educação. Além disso, também analisaram os efeitos de práticas corruptas sobre esses índices de eficiência. Os autores mostraram que a eficiência governamental tende a afetar os recursos públicos destinados às áreas de saúde e/ou educação, fato também verificado nos trabalhos desenvolvidos por Ribeiro (2008), Faria, Januzzi e Silva (2008) e Marinho, Cardoso e Almeida (2009).

Ainda segundo Lopes e Toyoshima (2013), um maior cuidado/controle sobre como os recursos públicos são utilizados nessas áreas se justifica pela importância delas para o desenvolvimento das regiões e países. Existe uma correlação positiva entre acumula- 
ção do capital humano e qualidade dos serviços de saúde e educação. Um maior capital humano contribui para a elevação da produtividade dos fatores, que auxilia, por sua vez, para o crescimento e desenvolvimento econômico de um país. Os autores chegam a esta conclusão baseados em trabalhos como os de Bose, Haque e Osborn (2003) e Romer (1989), que enfatizam a importância de se investir recursos adequados em serviços de saúde e educação como fonte de propagação do crescimento econômico.

É provável que níveis elevados de práticas corruptas no setor público possam provocar uma diminuição na eficiência desse mesmo setor. Por exemplo, quando ocorre a vitória, conquistada por meio de fraude, de uma empresa em um processo de licitação para ofertar determinado bem ou serviço ao setor público, fica claro que a mesma não é capaz de vencer a concorrência de forma lícita. Com isso, o setor público elege uma empresa que pode ofertar um serviço (ou bem) de qualidade inferior, o que reduz o retorno de cada unidade monetária paga pelo governo. Além disso, a subtração de parte dos recursos que seriam destinados ao gasto social para financiar tais obras, compromete a qualidade dos serviços de saúde e educação prestados pela sociedade.

Dessa forma, pode-se também afirmar que a produtividade do investimento público (em saúde e educação) é também comprometida por meio de superfaturamento de obras públicas (SVENSSON, 2005; TANZI, 1998; MAURO, 1995). Esse resultado foi encontrado mediante a associação entre eficiência governamental nos Estados brasileiros (como indicador de corrupção) por meio do método de Análise Envoltória de Dados (DEA)-BBC, com múltiplos estágios para os gastos governamentais da administração federal.

A análise dos resultados apresentados pelos trabalhos supracitados mostra que a corrupção pode diminuir a eficiência governamental. Com isso, ações de combate a essas práticas podem promover um maior nível de retorno dos recursos públicos destinados às áreas de saúde e educação, o que poderiam gerar um índice mais elevado de bem-estar social, bem como um crescimento econômico mais significativo. Ou seja, um elevado grau de corrupção pode estar associado a uma considerável redução no escore de eficiência governamental.

\section{METODOLOGIA}

\section{Base de Dados}

Os índices analisados neste trabalho provêm da plataforma web do Banco Mundial, intitulada Indicadores de Governança Mundial (Worldwide Governance Indicators), com dados para 33 países da América Latina e Caribe, referentes ao ano de 2015. Os indicadores de governança a serem utilizados (eficiência do governo e controle de corrupção) representam duas das seis dimensões analisadas na plataforma. ${ }^{4}$ Uma análise mais profunda sobre cada um dos índices escolhidos para o modelo está apresentada na terceira seção desta metodologia (modelo empírico).

\footnotetext{
${ }^{4}$ Os indicadores disponíveis pelo Banco Mundial são normalmente coletados por meio de pesquisa de campo junto a pessoas, empresas e especialistas da área de governança nos mais diversos países e paralelamente agregados a dados econômicos e sociais disponibilizados por uma variedade de empresas privadas, organizações internacionais e organizações não governamentais, incluindo institutos de pesquisa.
} 


\section{Modelos Econométricos}

O presente trabalho utilizará os métodos Ordinary Least Squares (OLS) e o método Tobit para estabelecer uma associação entre o controle da corrupção e a eficiência do governo. Além do índice de controle de corrupção, serão utilizados como variáveis explicativas outros cinco indicadores, apontados pela literatura delineada no referencial teórico deste trabalho, como fatores que podem impactar no índice de eficiência do governo. São eles: (i) gastos públicos com saúde; (ii) número de contrações no PIB per capita entre 1990-2015; (iii) índice de preço ao consumidor (IPC); (iv) consumo do governo; e, (iv) participação da administração pública no PIB.

A utilização do modelo Tobit justifica-se pela necessidade de realizar a análise de regressão desconsiderando o Haiti, país que apresentou sérios problemas estruturais ao longo desta década e que se encontrava (no momento da coleta de dados) ainda em fase de reconstrução de sua infraestrutura. O objetivo seria verificar, após a supressão do Haiti, se há diferenças nos resultados, entre as regressões Tobit e OLS, sobre as variáveis que impactam na eficiência do governo.

\section{Modelo Empírico}

A variável dependente do modelo empírico será dada pela Eficiência do Governo (doravante chamada EFIC_GOV), índice que varia entre zero e cem. Quanto mais próximo de cem, mais eficaz é o governo; quanto mais próximo de zero, mais ineficiente será a administração pública. De modo geral, este indicador traduz a percepção sobre a qualidade do serviço público prestado, o grau de independência em relação a pressões políticas, a qualidade de formulação e execução de políticas públicas e a capacidade do governo em cumprir tais políticas.

São várias as fontes utilizadas para a mensuração da variável EFIC_GOV. Ela é construída pelo Banco Mundial, com metodologia específica para agregar (em seu cálculo) informações relativas à qualidade da burocracia, o excesso de burocracia, a qualidade do ensino primário do país, a satisfação com estradas e rodovias, a satisfação com o sistema educacional, o nível de acesso à água potável e saneamento básico, o nível de acesso à energia elétrica, a área de cobertura e qualidade de infraestrutura de transportes (rodovias, ferrovias, aeroportos, portos), dentre outros indicadores extraídos de diversas outras fontes.

A variável independente do modelo será dada pelo Controle de Corrupção (variável CONTR_CORRUP), que também varia de zero a cem. Um valor igual a cem significa total controle sobre corrupção; valor igual a zero indica total descontrole sobre práticas corruptas. Este índice avalia o grau em que o poder público é usado para promover interesses alheios ao interesse comum do Estado.

Da mesma forma que a variável EFIC_GOV, a variável CONTR_CORRUP é mensurada a partir de várias fontes e indicadores distintos. Entre os indicadores que servem de base para a construção da variável CONTR_CORRUP estão: pagamentos irregulares em exportações e importações de bens e mercadorias, pagamentos irregulares feitos em serviços públicos, pagamentos irregulares em contratos públicos, pagamentos irregulares nas decisões judiciais, políticas anticorrupção, dentre outros. Ambas as variáveis EFIC_GOV e CONTR_CORRUP são elaboradas e divulgadas pelo Banco Mundial. 
Os demais índices abordados na análise de regressão, como possíveis variáveis explanatórias sobre a Eficiência do Governo, foram coletados por meio de duas fontes distintas. Os gastos públicos com saúde em porcentagem do PIB foram retirados do Relatório de Desenvolvimento Humano de 2016, publicado pela Organização das Nações Unidas (ONU). Os demais índices foram coletados na base de dados estatísticos e indicadores da Comissão Econômica para a América Latina e Caribe (CEPALSTAT). Todas essas variáveis estão especificadas em detalhes na Tabela 1.

Tabela 1 - Possíveis variáveis explanatórias dos modelos OLS e Tobit

\begin{tabular}{|c|c|c|c|c|}
\hline Abreviação & Nomenclatura & $\begin{array}{l}\text { Unidade de me- } \\
\text { dida }\end{array}$ & O que representa & Fonte \\
\hline GASTOS_SAUDE & \begin{tabular}{|lrr|}
\multicolumn{2}{|l}{ Gastos } & \multicolumn{2}{c|}{ públicos } \\
com saúde & em \\
relação & ao & PIB \\
$(2014)$. & & \\
\end{tabular} & $\begin{array}{l}\text { Variável contí- } \\
\text { nua, com valores } \\
\text { variando de zero } \\
\text { a cem. }\end{array}$ & $\begin{array}{l}\text { Razão entre o quanto } \\
\text { o governo gasta para } \\
\text { financiar gastos com } \\
\text { saúde e o PIB nacional. }\end{array}$ & ONU \\
\hline CONTR_PIB & $\begin{array}{l}\text { Número de anos } \\
\text { que apresentaram } \\
\text { contração econô- } \\
\text { mica entre } 1990 \text { e } \\
2015 .\end{array}$ & $\begin{array}{l}\text { Variável contí- } \\
\text { nua. }\end{array}$ & $\begin{array}{l}\text { Anos que apresenta- } \\
\text { ram contração do PIB } \\
\text { per capita em relação } \\
\text { ao ano anterior. }\end{array}$ & Cepal \\
\hline IPC_2010_2015 & $\begin{array}{l}\text { Média do Índice de } \\
\text { Preços ao Consu- } \\
\text { midor para o perío- } \\
\text { do 2010-2015. }\end{array}$ & $\begin{array}{l}\text { Variável contí- } \\
\text { nua. }\end{array}$ & $\begin{array}{l}\text { Valor médio das varia- } \\
\text { ções anuais nos preços } \\
\text { de bens e produtos } \\
\text { demandados e consu- } \\
\text { midos. }\end{array}$ & Cepal \\
\hline CONS_GOV & $\begin{array}{l}\text { Participação do } \\
\text { consumo do gover- } \\
\text { no no PIB a preços } \\
\text { correntes. }\end{array}$ & $\begin{array}{l}\text { Variável contí- } \\
\text { nua, com valores } \\
\text { variando de zero } \\
\text { a cem. }\end{array}$ & $\begin{array}{l}\text { Razão entre consumo } \\
\text { do governo e PIB a } \\
\text { preços correntes para } \\
2015 \text {. }\end{array}$ & Cepal \\
\hline PERC_ADM_P & $\begin{array}{l}\text { Valor agregado da } \\
\text { administração pú- } \\
\text { blica na composi- } \\
\text { ção do PIB a preços } \\
\text { correntes. }\end{array}$ & $\begin{array}{l}\text { Variável contí- } \\
\text { nua, com valores } \\
\text { variando de zero } \\
\text { a cem. }\end{array}$ & $\begin{array}{l}\text { Razão entre o valor } \\
\text { agregado da adminis- } \\
\text { tração pública e o PIB a } \\
\text { preços correntes para } \\
2015 .\end{array}$ & Cepal \\
\hline
\end{tabular}

As hipóteses básicas para as variáveis explanatórias do modelo empírico são dadas pelos seguintes argumentos:

a. Gastos Públicos com Saúde: governos que gastam mais em saúde tendem a elevar a quantidade e qualidade dos serviços prestados na área. A qualidade de serviços públicos de saúde pode afetar a eficiência governamental pelo fato de ser uma das áreas que mais demandam recursos públicos. Recursos direcionados à saúde, portanto, quando bem-empregados, podem influenciar positivamente a variável EFIC_GOV.

b. Contrações no PIB per capita: países que apresentam número elevado de contrações no PIB per capita estão apresentando maior volatilidade no seu crescimento econômico. A instabilidade econômica, provocada por quedas do PIB per capita, pode gerar incertezas em relação ao futuro do consumo da sociedade, atrelado (direta ou indiretamente) a essa variável. Esta variável tam- 
bém pode influenciar a percepção e a avaliação que a sociedade e mercados têm sobre o governo, o que pode afetar a credibilidade do mesmo e, como consequência, as avaliações relacionadas à eficiência governamental.

c. Índice de Preço ao Consumidor: países com elevadas taxas de inflação tendem a apresentar baixa eficiência governamental, dado o consecutivo aumento de gastos públicos com redução de receita. Além disso, países com elevadas taxas de inflação provavelmente falharam em suas políticas monetárias. Como consequência, esses governos tendem a falhar em seus resultados de eficiência.

d. Consumo do Governo: quanto maior for o consumo do governo dentro de uma economia, maior será o tamanho do Estado e maior será a interferência reguladora do mesmo nos mercados. O Estado muito "robusto" pode contribuir para que seu funcionamento não seja tão eficiente comparado a um Estado que gerencia apenas suas finalidades primordiais.

e. Participação da Administração Pública no PIB: Variável que engloba as despesas com defesa, educação e saúde, além de programas e serviços sociais em porcentagem do valor agregado do PIB a preços correntes de 2015. Uma administração pública muito robusta talvez não seja desejável pelos mesmos motivos apresentados para a variável "consumo do governo" (d).

\section{RESULTADOS}

Esta seção é subdividida em três tópicos. O primeiro tópico irá apresentar uma análise descritiva das variáveis que serão abordadas no modelo econométricos, bem como os resultados gerais para os países da amostra. O segundo tópico apresentará os resultados da estimativa de um modelo de regressão elaborado pelos métodos OLS e Tobit.

\section{Análise Descritiva}

Para que seja possível uma maior compreensão da variável Eficiência do Governo, bem como das possíveis variáveis que possam impactar nesse índice, além do Controle de Corrupção, será realizada uma análise das correlações das variáveis explanatórias do modelo com a variável EFIC_GOV.

Os países que fazem parte da amostra estudada são: Antígua e Barbuda, Argentina, Bahamas, Barbados, Belize, Bolívia, Brasil, Chile, Colômbia, Costa Rica, Cuba, Dominica, El Salvador, Equador, Granada, Guatemala, Guiana, Haiti, Honduras, Jamaica, México, Nicarágua, Panamá, Paraguai, Peru, República Dominicana, Santa Lúcia, São Cristóvão e Nevis, São Vicente e Granadinas, Suriname, Trinidad e Tobago, Uruguai e Venezuela, totalizando 33 países que correspondem a quase totalidade dos países que constituem o continente americano, 94,3\%.

De forma geral, apenas oito países (24,24\% da amostra) apresentaram valores, para a variável CONTR_CORRUP, superiores a 70. A média do controle da corrupção para a América Latina e Caribe é de apenas 47,42 , sendo 20 países (60,6\% da amostra) identificados com controle de corrupção abaixo de 50. Com isso, fica evidente que o descontrole sobre práticas corruptas é endêmico na amostra. A Eficiência do Governo 
também não é elevada para a média de países da amostra (com média estimada em torno de 47,27$)$. Apenas quatro países $(12,12 \%$ da amostra) obtiveram valores iguais ou superiores a 70: Bahamas (74), Barbados (80), Chile (83) e Uruguai (73).

A correlação entre as variáveis CONTR_CORRUP e EFIC_GOV é apresentada no Gráfico 1. O Controle de Corrupção possui uma forte correlação linear positiva com a Eficiência do Governo, com índice equivalente a 0,7942. Níveis altos de controle sobre práticas corruptas estão associados a níveis também elevados de eficiência nas administrações públicas e vice-versa. Com isso, pode-se inferir que o Controle de Corrupção possa explicar as variações em Eficiência do Governo.

A forte correlação positiva entre a variável EFIC_GOV e a variável CONTR_CORRUP é visualmente perceptível. Países que apresentam baixos valores para eficiência governamental também possuem baixos escores de controle sobre práticas corruptas.

A Venezuela é o país que tem a pior avaliação em CONTR_CORRUP, com escore 6. Os venezuelanos possuem, ainda, o segundo governo mais ineficiente da amostra analisada, com nota 11 para EFIC_GOV. O Haiti apresenta situação similar, com o governo mais ineficiente da amostra (com escore 1 ), enquanto a variável CONTR_CORRUP haitiana é a segunda mais baixa (9). Outros países, apesar de estarem em situação melhor que Venezuela e Haiti, também apresentaram baixos escores (inferiores a 50) para ambas as variáveis EFIC_GOV e CONTR_CORRUP. São eles: Bolívia, Brasil, Belize, EI Salvador, Equador, Guatemala, Guiana, Honduras, Nicarágua, Paraguai, Peru, República Dominicana e Suriname.

No cenário contrário ao da Venezuela e do Haiti, estão Bahamas, Barbados, Chile e Uruguai. Todos esses países apresentaram excelentes avaliações para ambas as variáveis analisadas no Gráfico 1, com escores superiores a 70.

Gráfico 1 - Dispersão dos países por Controle de Corrupção e Eficiência do Governo

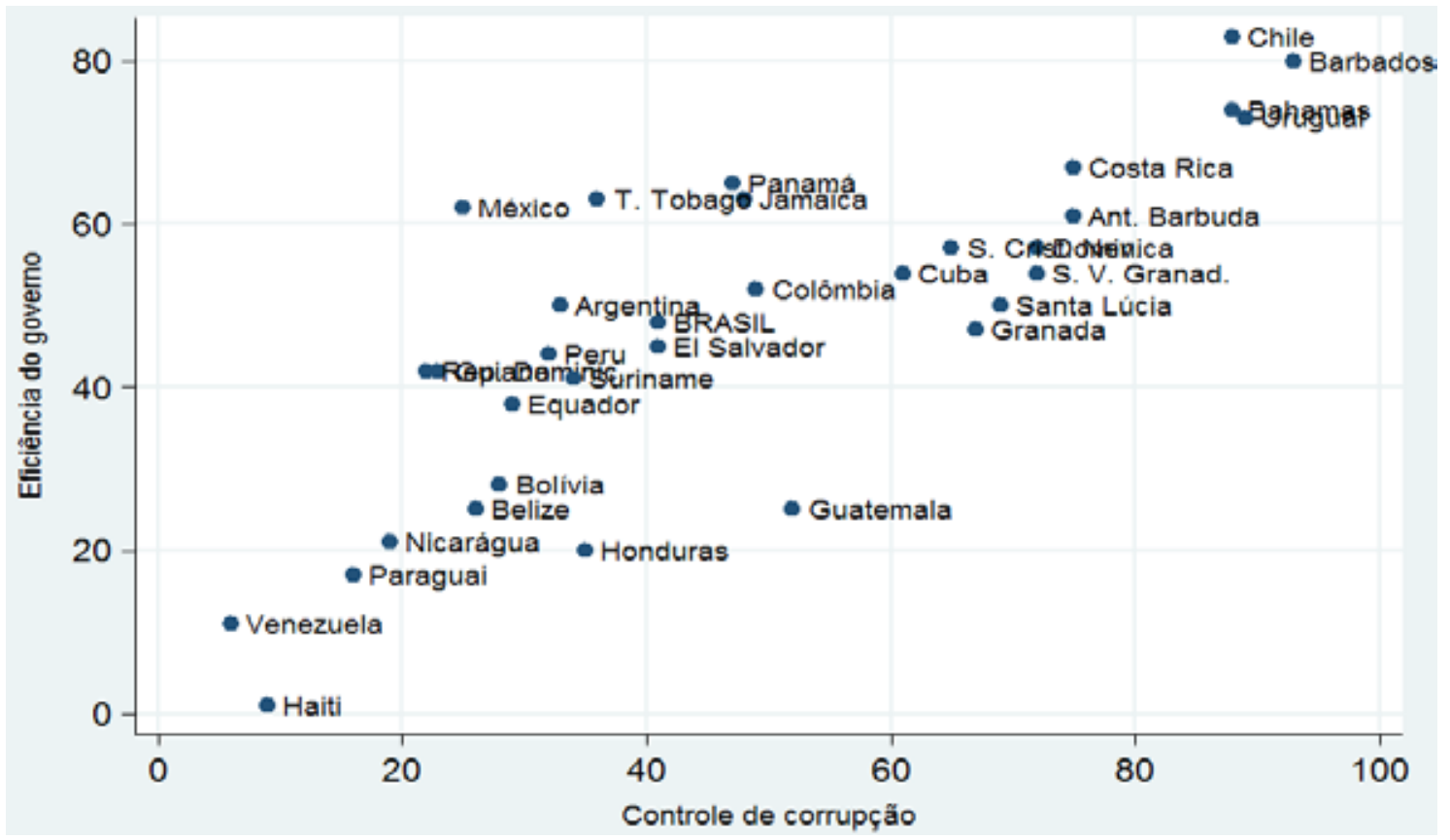

Fonte: BANCO MUNDIAL, 2015. 
A Tabela 2, a seguir, apresenta o sumário descritivo de todas as variáveis analisadas neste trabalho, bem como os desvios-padrão e os maiores e menores valores observados para cada variável, para que seja possível uma visão global sobre elas.

Tabela 2 - Sumário estatístico das variáveis utilizadas nos modelos OLS e Tobit

\begin{tabular}{|l|c|c|c|c|}
\hline Variável & Média & Desvio-padrão & Mínimo & Máximo \\
\hline EFIC_GOV & 47.27273 & 20.16537 & 1 & 83 \\
\hline CONTR_CORRUP & 47.42424 & 25.05997 & 6 & 93 \\
\hline GASTOS_SAUDE & 4.012121 & 1.703812 & 1.5 & 10.6 \\
\hline CONTR_PIB & 6.575758 & 3.31691 & 1 & 14 \\
\hline IPC_2010_2015 & 6.108485 & 10.62774 & 0.8 & 62.7 \\
\hline CONS_GOV & 14.91818 & 4.778366 & 7.2 & 32.4 \\
\hline PERC_ADM_P & 20.64545 & 6.915973 & 6 & 37 \\
\hline
\end{tabular}

Fonte: Elaboração própria.

Para uma análise mais completa dos dados apresentados na Tabela 2, cada variável será analisada individualmente. Para que a análise fique mais clara, a amostra de países será dividida em três grupos de acordo com os valores observados da variável EFIC_GOV: o grupo dos países eficientes, que apresentam escores iguais ou superiores a 70; o dos países com eficiência moderada, que possuem escores variando entre 50 e 69; e, por fim, o dos países ineficientes, que têm valores para a variável EFIC_GOV inferiores a 50 .

Os países com governos eficientes são apenas quatro, representando $12,12 \%$ da amostra. Os países com eficiência moderada totalizam 13 observações, o que representa $39,4 \%$ do total de países. Já os países com governos ineficientes perfazem 16 observações, o que representa quase metade da amostra, 48,5\%. O Gráfico 2 apresenta os escores em EFIC_GOV para cada país da Amostra.

O escore de eficiência do governo brasileiro, na amostra analisada, é de 48, valor muito próximo à média da amostra de países. Dos países, 17 possuem governos mais eficientes que o brasileiro: Chile (83), Barbados (80), Bahamas (74), Uruguai (73), Costa Rica (67), Panamá (65), Jamaica (63), Trinidad e Tobago (63), México (62), Antígua e Barbuda (61), Dominica (57), São Cristóvão e Nevis (57), Cuba (54), São Vicente e Granadinas (54), Colômbia (52) Argentina (50) e Santa Lúcia (50).

A correlação linear entre Controle de Corrupção e Eficiência do Governo é positiva (como explanado na seção anterior), o que pode indicar que o maior controle sobre a corrupção pode, de fato, influenciar, positivamente, os níveis de eficiência do governo. 
Gráfico 2 - Eficiência do Governo

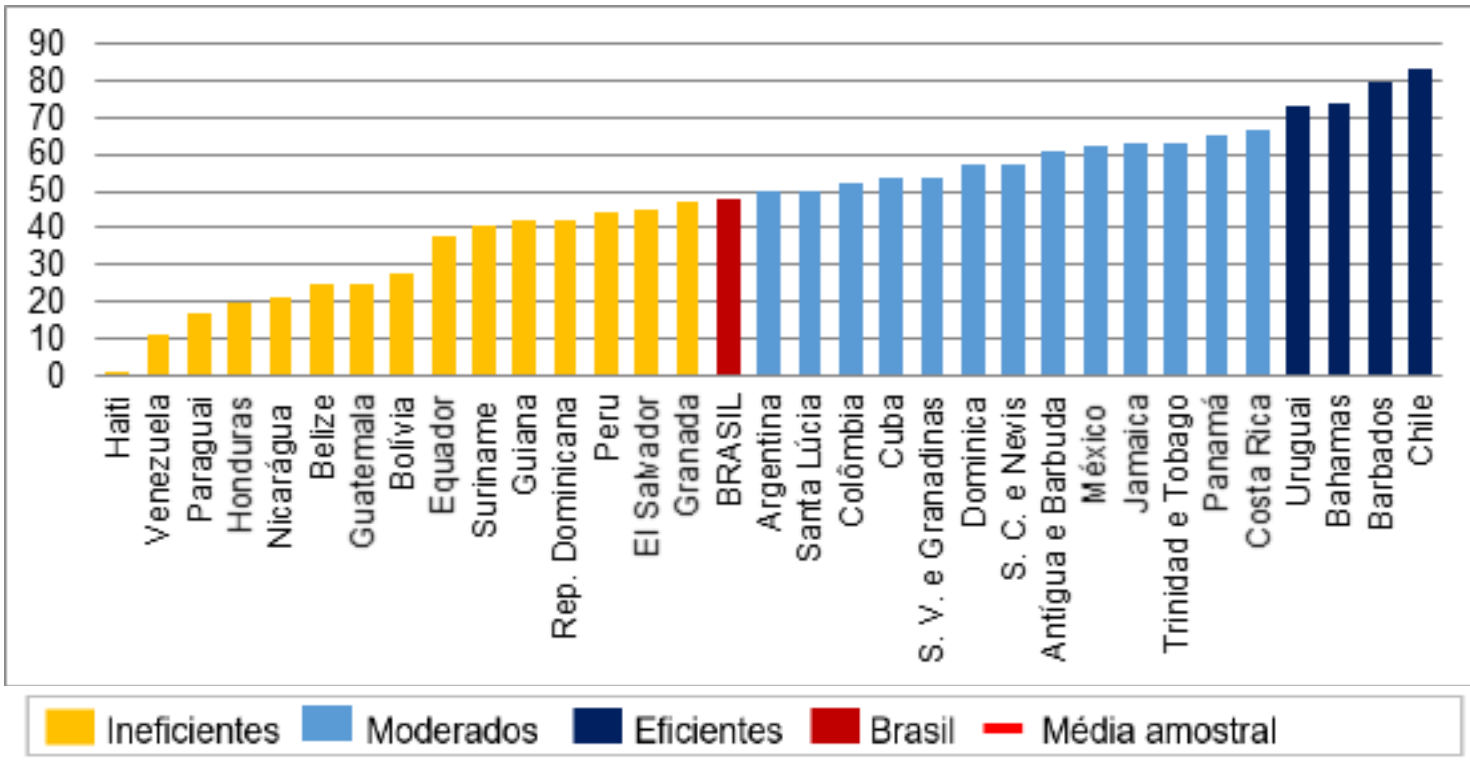

Fonte: BANCO MUNDIAL, 2015.

O Gráfico 3 contribui um pouco mais para a compreensão da relação entre controle de corrupção e a eficiência dos governos analisados. Países com governos eficientes apresentaram média de Controle de Corrupção em torno de 89,5, valor que se traduz num elevado controle sobre o problema da corrupção. Já os países com eficiência moderada obtiveram média mais modesta $(55,9)$, o que representa um controle mais ameno sobre as práticas corruptas. Os países com governos ineficientes apresentaram escores médios de controle de corrupção ainda mais baixos (estimado em 30), valor bem inferior à média amostral $(47,42)$, o que mostra falta de controle sobre a corrupção nesses países.

Gráfico 3 - Controle de Corrupção

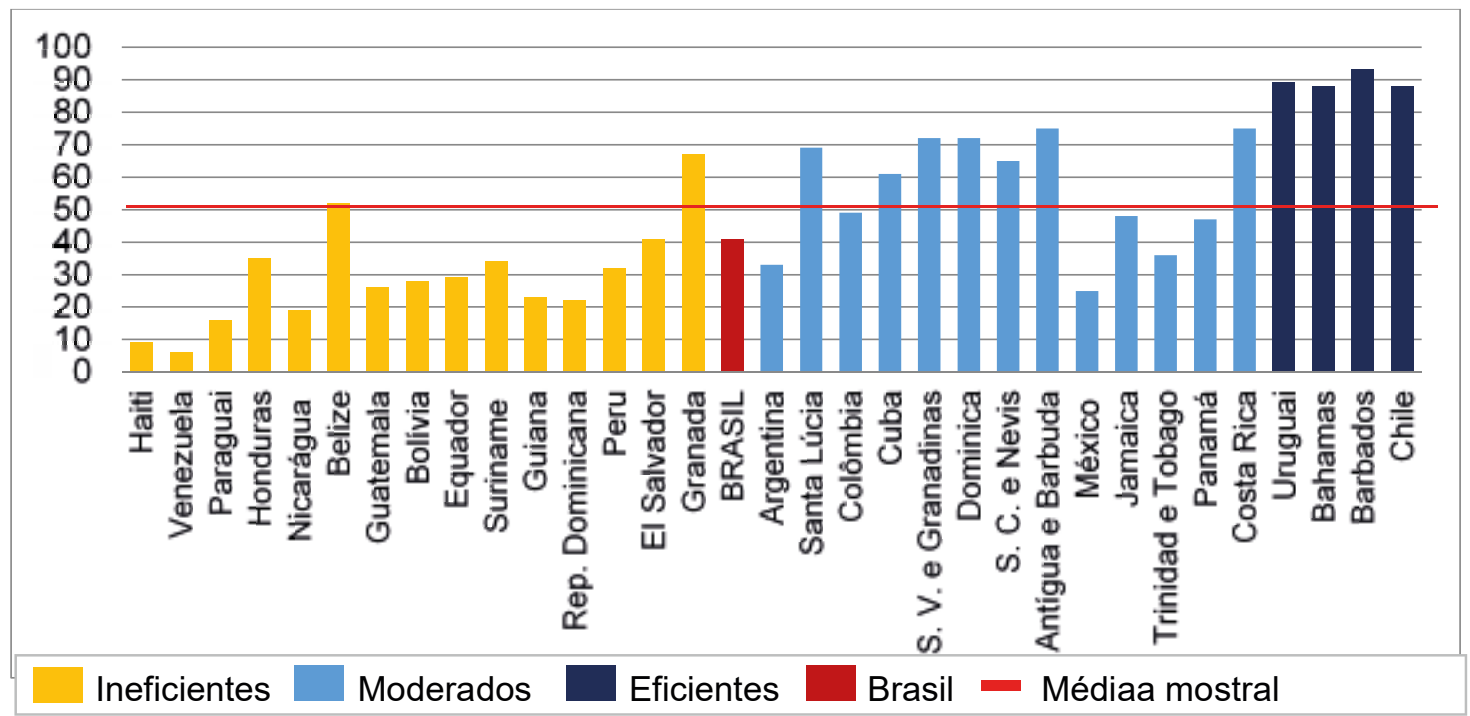

Fonte: BANCO MUNDIAL, 2015. 
O Brasil possui Controle de Corrupção inferior à média da América Latina e Caribe, com escore fixado em 41. Cerca de 16 nações latino-americanas possuem maior controle sobre práticas corruptas que o apresentado pelo Brasil: Barbados (93), Uruguai (89), Bahamas (88), Chile (88), Antígua e Barbuda (75), Costa Rica (75), Dominica (72), São Vicente e Granadinas (72), Santa Lúcia (69), Granada (67), São Cristóvão e Nevis (65), Cuba (61), Belize (52), Colômbia (49) Jamaica (48) e Panamá (47).

O Gráfico 4 apresenta os valores atribuídos para a variável GASTOS_SAUDE para todos os países da amostra divididos nos três grupos de eficiência governamental. Existe, para a amostra, uma correlação linear positiva entre GASTOS_SAUDE e EFIC_GOV com valor equivalente a 0,2958 . Dada a média amostral de gastos com saúde estimada em 4,01\% do PIB, países com governos eficientes gastam, em média, 4,57\% do PIB com saúde, um resultado superior à média amostral. Os países com governos de eficiência moderada consomem 4,49\% do PIB em saúde. Países com governos ineficientes comprometem apenas $3,48 \%$ do seu PIB com gastos relacionados à saúde, portanto um valor inferior à média amostral. Os dados mostram que há também uma queda marginal nos gastos com saúde quando se migra dos países eficientes para os ineficientes.

Em relação aos gastos públicos com saúde em porcentagem do PIB, o Brasil gasta um pouco menos que a média amostral dos países da América Latina e Caribe (3,8\%), ficando atrás de 15 países nesta classificação, tais como: Cuba (10,6\%), Costa Rica $(6,8 \%)$, Uruguai $(6,1 \%)$, Panamá $(5,9 \%)$, Colômbia $(5,4 \%)$, Nicarágua $(5,1 \%)$, Barbados $(4,7 \%)$, Bolívia (4,6\%), El Salvador (4,5\%), Equador (4,5\%), Paraguai (4,5\%), São Vicente e Granadinas (4,4\%), Honduras (4,4\%), Chile $(3,9 \%)$ e Belize $(3,9 \%)$.

Gráfico 4 - Gastos públicos com saúde (\% do PIB)

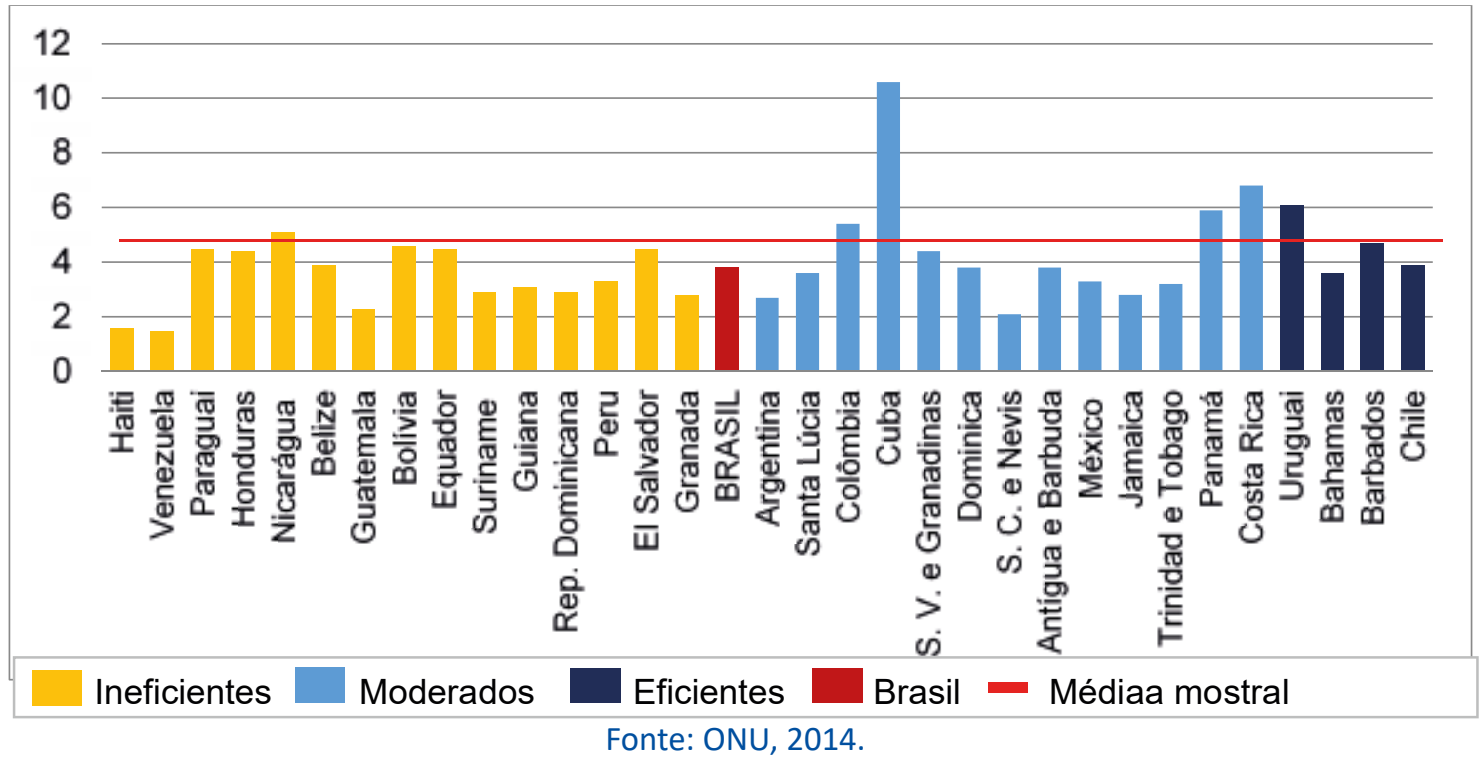

O Gráfico 5 apresenta os valores atribuídos à variável CONTR_PIB para todos os países da amostra. Os resultados mostram uma correlação linear negativa entre EFIC_ GOV e CONTR_PIB, estimada num valor equivalente a -0,1435. Entre 1990 e 2015, os países com governos eficientes tiveram, em média, 7,75 anos de queda no PIB per capi$t a$, um valor acima da média amostral (6,57 anos). Os países com governos em eficiência moderada tiveram 6,23 anos de contração no PIB per capita, enquanto os países 
com governos ineficientes tiveram, em média, 6,56 anos com contração no PIB per capi$t a$. Vale ressaltar que os países de eficiência moderada e ineficientes obtiveram a menor quantidade de contração no PIB per capita, um resultado curioso.

O Brasil apresentou um total de dez anos com contrações do PIB per capita entre o período de 1990 a 2015, um valor muito superior à média dos países da amostra (6,6 anos). Apenas quatro países da amostra tiveram maior número de contrações do PIB per capita [Bahamas (14), Santa Lúcia (13), Haiti (12) e Venezuela (11)].

O Gráfico 6 apresenta as médias das variações anuais do Índice de Preços ao Consumidor para os anos de 2010 a 2015 (IPC_2010_2015) para cada grupo de eficiência. A hipótese básica é que uma inflação maior impacta negativamente na eficiência do governo. Os resultados obtidos no Gráfico 5 contribuem para respaldar essa premissa. Países com governos eficientes tiveram um IPC médio de 4,05\%, portanto abaixo da média da amostra (estimada em 6,11\%). O IPC dos países de eficiência moderada foi um pouco maior (4,33\%). Já os ineficientes obtiveram um IPC acima da média da amostra, com valor igual a 8,07\%. A correlação entre as variáveis IPC_2010_2015 e EFIC_GOV foi de 0,3401 .

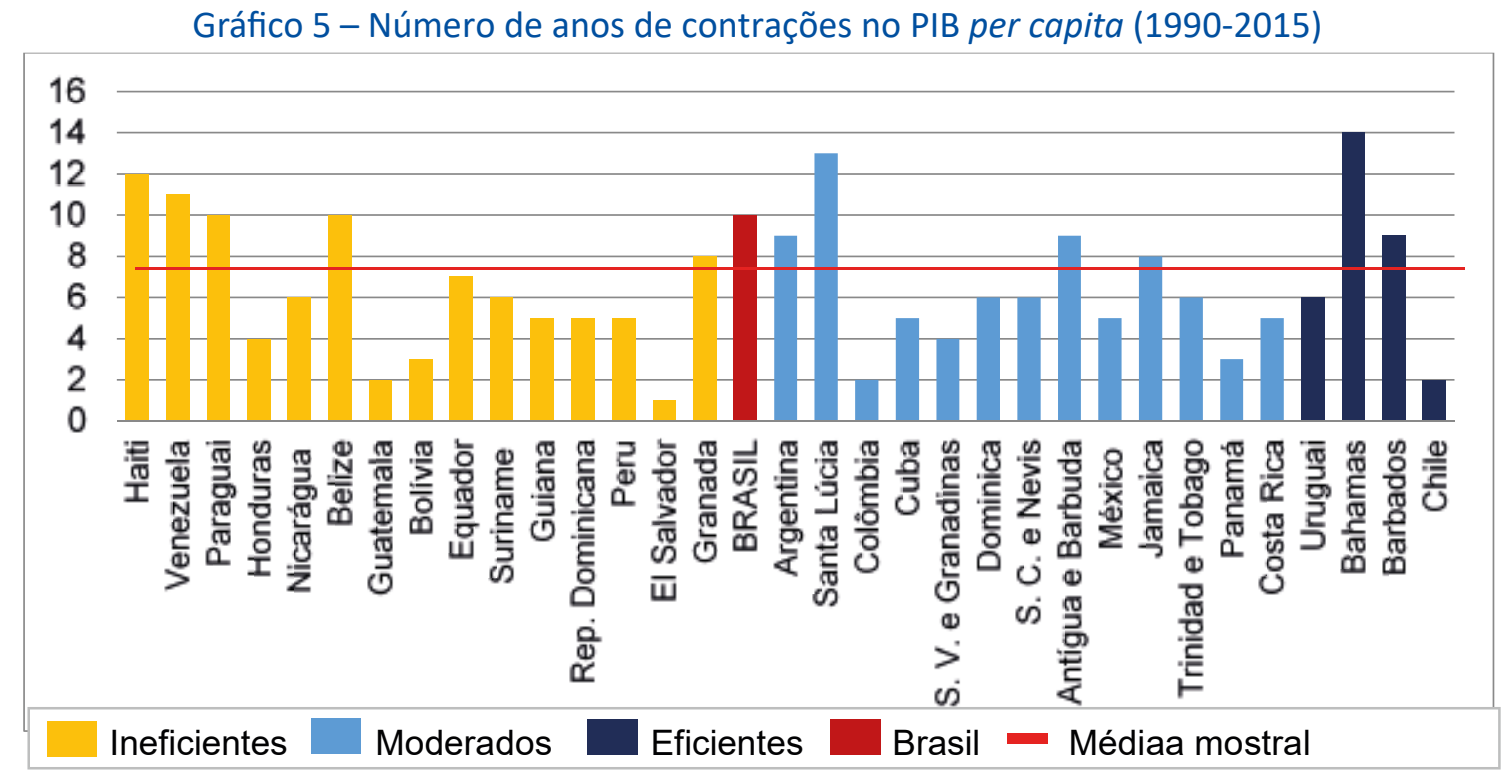

Fonte: CEPALSTAT, 2015.

O Gráfico 7 expõe os valores médios para a variável Consumo do Governo em porcentagem do PIB (CONS_GOV) para cada um dos três grupos de eficiência da amostra. Os valores apresentados para os grupos se mostram inconclusivos. Países com governos eficientes apresentaram um consumo de $14,77 \%$ em relação ao PIB, bem próximo, mas abaixo, da média da amostra (14,92\%). Os países com governos de eficiência moderada apresentaram consumo mais robusto $(17,17 \%)$ e superior à média amostral. Os países ineficientes apresentaram um consumo agregado médio mais reduzido que o dos eficientes (13,11\%). A correlação entre as variáveis CONS_GOV e EFIC_GOV apresentou valor equivalente a 0,2897. 
Os resultados observados no Gráfico 7 mostram que o Estado brasileiro é bem "robusto", e o consumo do governo brasileiro em porcentagem do PIB nacional é de $20,4 \%$, bem maior que a média de todos os países avaliados (14,92\%). Apenas três governos latino-americanos possuem uma razão Consumo do Governo/PIB superior à brasileira: Cuba (32,4\%), Dominica (22,3\%) e São Vicente e Granadinas (22,2\%).

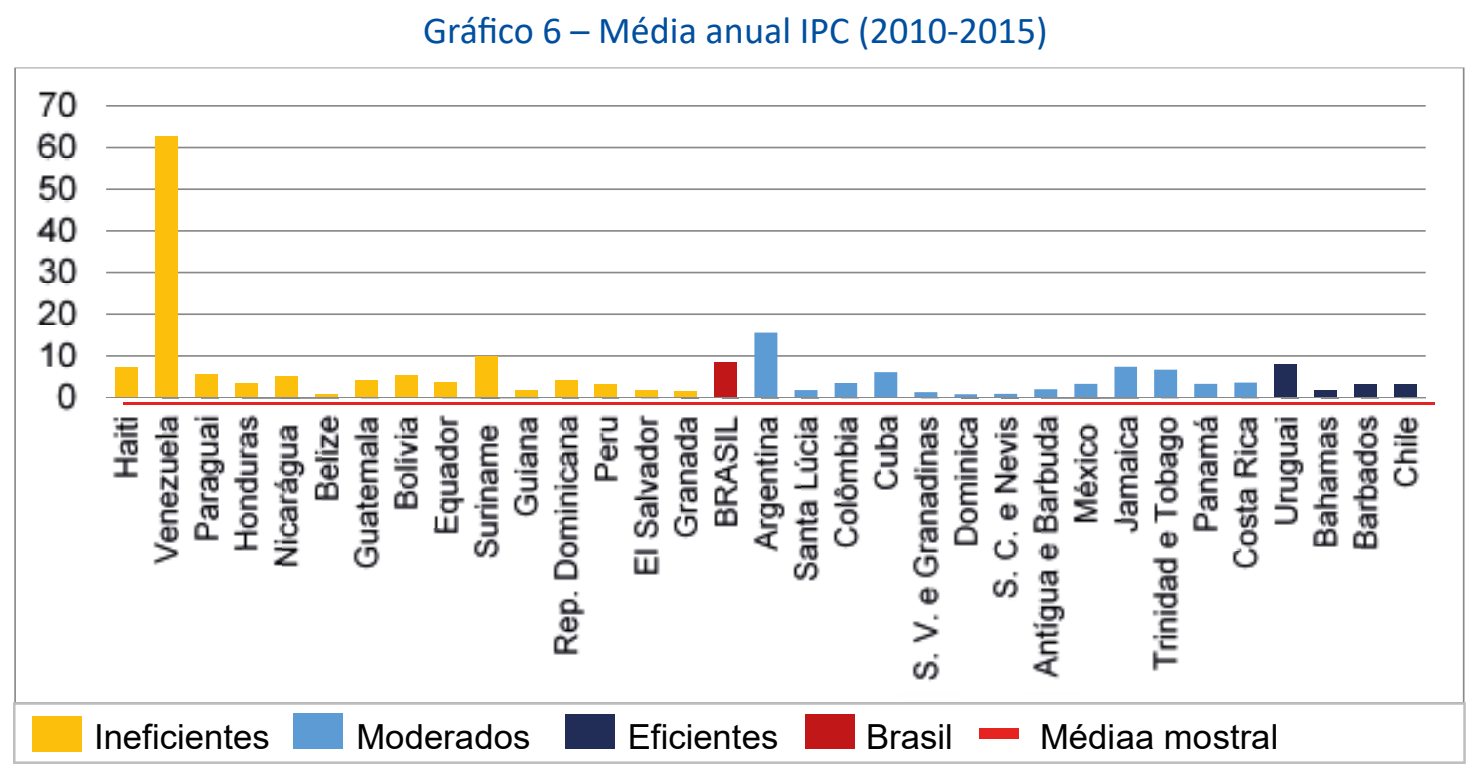

Fonte: CEPALSTAT, 2015.

Gráfico 7 - Consumo do Governo (\% do PIB)

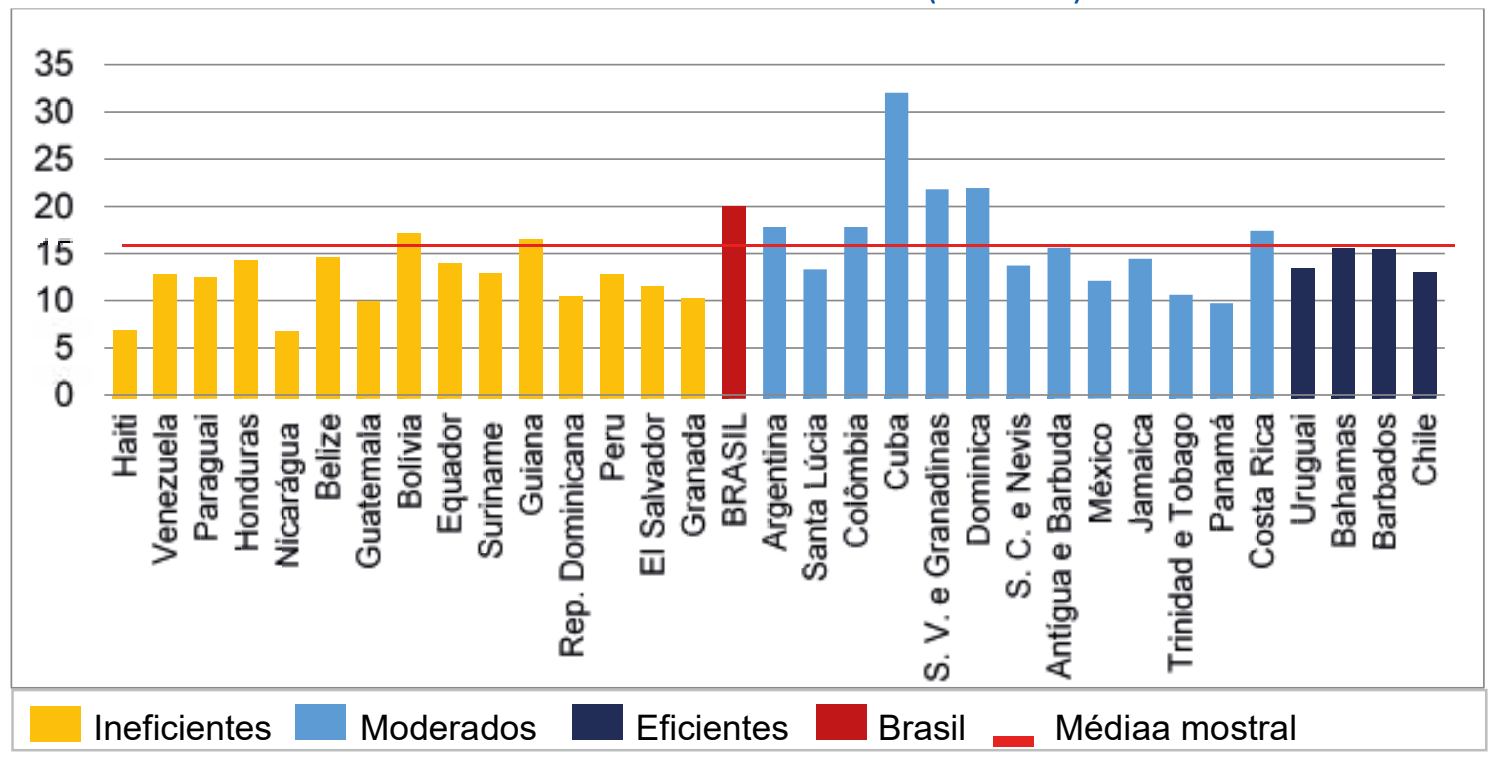

Fonte: CEPALSTAT, 2015.

O Gráfico 8 apresenta a relação entre o tamanho do Estado e os grupos de eficiência analisados. Os países enquadrados como eficientes possuem uma PERC_ADM_P aproximado de $22,95 \%$, um valor pouco superior à média da amostra $(20,64 \%)$. Os países com governos de eficiência moderada também apresentaram valor médio supe- 
rior à media geral, sendo estimado em $21,24 \%$. Por fim, os países com governos ineficientes obtiveram percentual médio equivalente a 19,58\%, um valor abaixo da média da amostra.

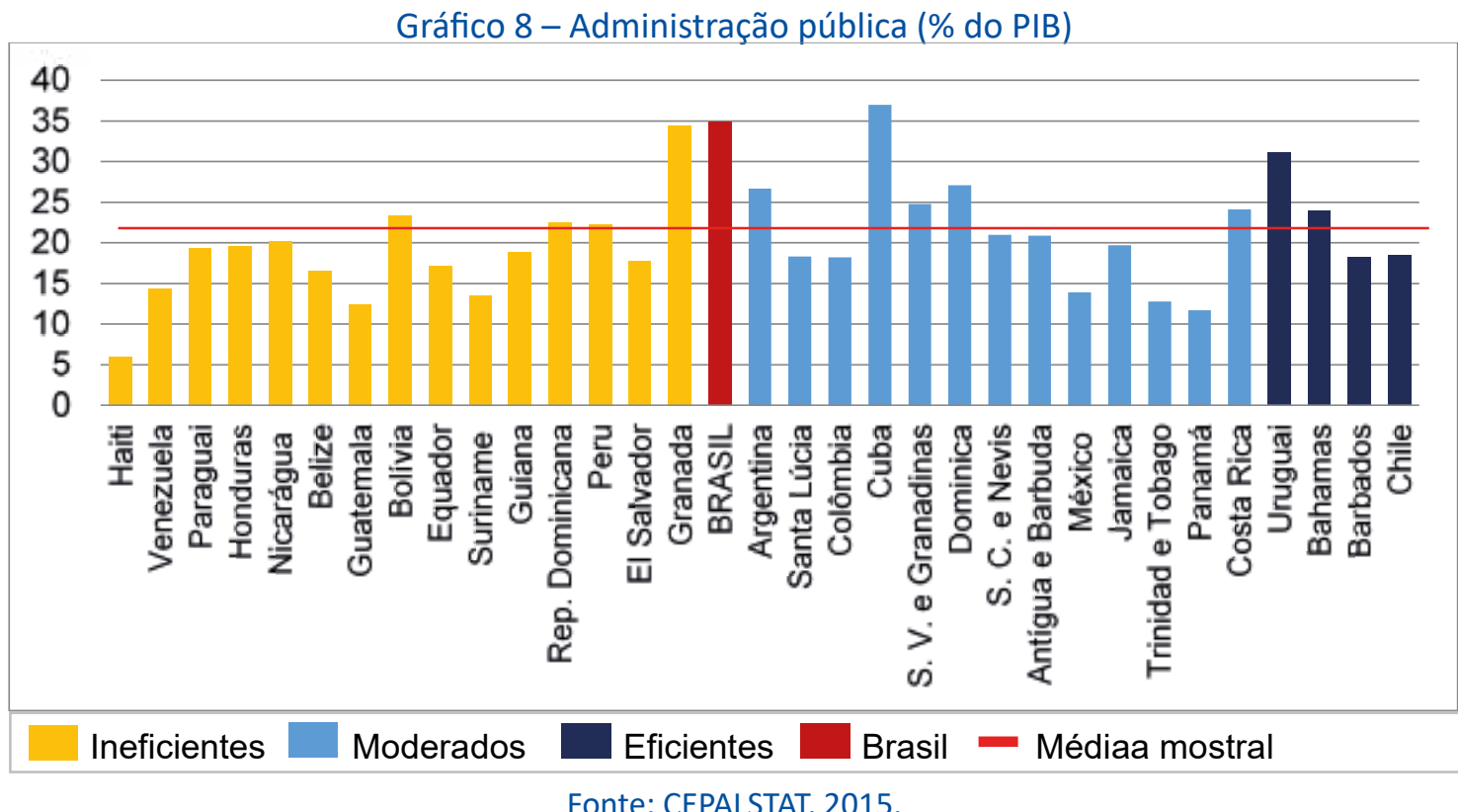

O tamanho da administração pública brasileira (34,9\%) é o segundo maior da América Latina e Caribe. Apenas Cuba possui uma administração pública mais robusta que a brasileira, fixada em $37 \%$.

\section{Estimativa pelos métodos OLS e Tobit}

A descrição das variáveis e dos resultados gerais apresentada no tópico anterior, apesar de apresentar uma visão mais aprofundada das variáveis e de suas correlações com a variável explicada, não apresentou evidências claras sobre seus possíveis impactos na variável EFIC_GOV. Com o intuito de determinar se, de fato, essas variáveis são capazes de afetar as variações na eficiência governamental, além de buscar dimensionar o nível de influência sobre a mesma, caso haja, o presente tópico desenvolverá um modelo de regressão linear utilizando toda a amostra que serviu de base para a caracterização da seção anterior.

A Tabela 4 mostra o resultado da estimação OLS para a variável EFIC_GOV, dadas as variáveis explanatórias utilizadas para explicar a problemática da eficiência do governo. 
Tabela 4 - Modelo de regressão estimado pelo método de OLS

(variável dependente: eficiência do governo)

\begin{tabular}{l|l|l}
\hline Discriminação & Coeficiente estimado & Erro-padrão \\
\hline Constante & 26.48383 & 9.896529 \\
\hline Controle de Corrupção & $0.6703094^{*}$ & 0.1119499 \\
\hline Gastos públicos com saúde & $-0.5946281^{\text {NS }}$ & 1.814112 \\
\hline Contrações do PIB & $-1.223536^{\text {NS }}$ & 0.7698706 \\
\hline IPC (2010-2015) & $0.0214366^{\text {NS }}$ & 0.2481678 \\
\hline Consumo do Governo & $0.0976874^{\text {NS }}$ & 0.6968103 \\
\hline Administração pública & $-0.1044728^{\text {NS }}$ & 0.4491044 \\
\hline$R^{2}$ & 0.6675 & \\
\hline$F(6,26)$ & $8.70^{*}$ & \\
\hline Número de observações & 33 & \\
\hline
\end{tabular}

Fonte: Elaboração própria.

Nota: ${ }^{*}$ significância a $1 \%, * *$ significância a 5\%, *** significância a $10 \%$, NS: não significante.

Os resultados obtidos com a estimação em questão foram satisfatórios e válidos, uma vez que o teste $\mathrm{F}$ calculado é estatisticamente significante a menos de $1 \%$ de significância, o que aponta para um bom ajustamento dos coeficientes estimados ao modelo. $O \mathrm{R}^{2}$ apresentou um valor satisfatório de 0,6675 , o que representa um bom ajustamento do modelo aos dados embutidos. O modelo é, portanto, capaz de explicar $66,75 \%$ das variações na variável explicada (EFIC_GOV).

Além disso, foram utilizadas duas categorias de testes para identificar problemas que são comuns em estimativas desse tipo: o teste do Fator de Inflação da Variância (VIF), para identificar a existência de multicolinearidade, e, os testes de Breusch-Pagan-Goodfrey e de White, para detectar a presença de heteroscedasticidade. O teste VIF apresentou valores abaixo do valor, o que pode indicar problema de multicolinearidade para todas as variáveis estimadas. Os testes Breusch-Pagan-Goodfrey e White também aceitaram a hipótese nula de homocedasticidade.

O Controle de Corrupção foi a única variável significante do modelo, com nível de significância inferior a 1\%. Assim, a variável CONTR_CORRUP está apta para explicar a variável EFIC_GOV. As demais variáveis foram não significantes.

O Controle de Corrupção possui um efeito marginal equivalente a 0,6703, com nível de significância inferior a 1\%, indicando que tal variável pode explicar grande parte das variações em EFIC_GOV. Como já especificado na Metodologia, a variável CONTR_ CORRUP, assim como a variável EFIC_GOV, varia de zero a cem. Se, portanto, houver o aumento de um ponto na variável CONTR_CORRUP, esse aumento gerará um acréscimo de 0,67 pontos na variável EFIC_GOV. A título de comparação, e supondo que exista um país representado pela média amostral da eficiência do governo (47), atrelada ao 
valor médio da variável CONT_CORRUP (47) da amostra, estima-se que se o controle de corrupção desse país passasse de 47 para 79, esse país conquistaria a eficiência governamental máxima (cem).

A regressão Tobit foi estimada com as mesmas variáveis utilizadas na estimativa OLS, mas, conforme especificações delineadas na seção "modelo econométrico" deste trabalho, truncando o país com o menor valor para a variável EFIC_GOV, equivalente a um (1), dada pelo Haiti. O Haiti é um caso extremo de ineficiência governamental, até mesmo para a América Latina e Caribe. Prova disso é que a Venezuela, segundo governo mais ineficiente da amostra de países analisados, apresenta escore para a variável EFIC_GOV equivalente a 11 (10 pontos acima do Haiti). Além disso, o Haiti apresenta o menor nível de desenvolvimento humano em todo o continente americano (composto por 35 países). Apenas 24 dos 188 países avaliados no Relatório de Desenvolvimento Humano da ONU apresentaram um IDH inferior ao haitiano. Por conta da grande disparidade entre a situação que se encontra o Haiti quando comparado aos demais países da amostra, a integração do mesmo ao grupo de países pouco contribui para a análise pretendida. Desse modo, o Haiti foi truncado da amostra neste modelo de regressão.

A Tabela 5, a seguir, apresenta o resultado da estimativa pelo modelo Tobit para a variável EFIC_GOV, dadas as variáveis explanatórias utilizadas para explicar as variações da eficiência do governo.

Tabela 5 - Modelo de regressão estimado pelo modelo Tobit (variável dependente: eficiência do governo)

\begin{tabular}{l|l|l}
\hline Discriminação & Coeficiente estimado & Erro-padrão \\
\hline Constante & 25.61341 & 9.049378 \\
\hline Controle de corrupção & $0.6799691^{*}$ & 0.1023522 \\
\hline Gastos públicos com saúde & $-0.6208283^{\mathrm{NS}}$ & 1.652627 \\
\hline Contrações do PIB & $-1.338739^{* * *}$ & 0.7090612 \\
\hline IPC (2010-2015) & $0.0406802^{\mathrm{NS}}$ & 0.2267308 \\
\hline Consumo do Governo & $0.0970105^{\mathrm{NS}}$ & 0.6347171 \\
\hline Administração pública & $-0.0562683^{\mathrm{NS}}$ & 0.4114299 \\
\hline Sigma & 11.75088 & \\
\hline Pseudo- ${ }^{2}$ & 0.1256 & \\
\hline LR qui-quadrado (6) & $36.01^{*}$ & \\
\hline Log likelihood (modelo completo) & -125.40859 & \\
\hline Número de observações & 32 & \\
\hline
\end{tabular}

Fonte: Elaboração própria.

Nota: ${ }^{*}$ significância a $1 \%, * *$ significância a $5 \%, * * *$ significância a $10 \%$, NS: não significante.

Mediante o Teste de Razão de Verossimilhança (LR), verifica-se que o modelo apresentado é válido, com um nível de significância inferior a 1\%, o que aponta para um bom ajustamento conjunto dos coeficientes estimados ao modelo. A significância da estatística qui-quadrado (inferior a 1\%) também contribui para a mesma percepção. 
O Controle de Corrupção, mais uma vez, apresenta-se como uma variável explanatória estatisticamente significante, com nível de significância inferior a 1\% e, portanto, apta a explicar a variável EFIC_GOV. O Controle de Corrupção possui um efeito marginal equivalente a 0,68 , indicando que o aumento de um ponto na variável CONTR_CORRUP geraria um acréscimo de 0,68 pontos na variável EFIC_GOV.

A segunda variável significante do modelo Tobit foi CONTR_PIB, a 10\%. Ou seja, o número de anos de contração no PIB per capita entre o período de 1990 e 2015 pode explicar parte das variações da eficiência do governo. Nesse caso específico, um ano a mais de contração do PIB per capita provocaria uma queda de -1,34 ponto no escore de eficiência do governo. A título de exemplo, 14 anos de contrações no PIB per capita (maior valor atribuído à variável entre as observações da amostra) seria capaz de reduzir a eficiência do governo em 18,62 pontos. As demais variáveis explicativas do modelo foram não significantes.

\section{CONSIDERAÇÕES FINAIS}

É unanimidade entre as pesquisas apresentadas neste trabalho, bem como ao senso comum, de que corrupção é um mal para as sociedades e que deve ser combatido ou controlado. A presença endêmica de corrupção está associada a países que permitem o desenvolvimento de instituições políticas que exploram as sociedades por meio da transferência de recursos do povo para os agentes envolvidos em práticas corruptas. Trata-se da inversão do papel do Estado, que deveria ser o promotor do progresso social da nação, mas que leva a falhas graves nas eficiências dos governos, gerando inúmeros problemas, como desvios de recursos públicos, ineficiência no funcionamento das instituições públicas, inadequada infraestrutura de transportes, programas de governo não cumpridos, dentre outros.

Os resultados mostram que, dentro da América Latina, baixos níveis de controle de corrupção tendem a reduzir a eficiência dos Estados-membros pertencentes ao grupo, o que se reverte em sociedades penalizadas, com grupos sociais pobres que dependem intensamente do amparo do Estado. Além disso, há indicações teóricas que relacionam a ineficiência dos serviços públicos de saúde, educação, programas sociais, saneamento, dentre outros, como consequência da ampliação das práticas corruptas. Há, portanto, indicações de que a corrupção pode, portanto, comprometer negativamente a alocação eficiente dos recursos em geral, gerando ineficiência e queda de produtividade.

Os resultados apresentados neste trabalho apontam para o quadro de corrupção endêmica e generalizada na América Latina e Caribe. Vinte países (60,6\% da amostra) apresentaram escores de Controle de Corrupção inferiores a 50, inclusive o Brasil (41). Nesses países, portanto, o Controle de Corrupção é muito baixo.

O presente trabalho atentou para a gravidade da problemática da corrupção no âmbito da qualidade dos governos nacionais. Dados os diversos indicadores analisados, além do controle de corrupção, os resultados obtidos pelas regressões dos métodos OLS e Tobit mostraram que o controle de corrupção gera um impacto positivo significativo nas variações em eficiência governamental. Ou seja, quanto maior o controle sobre práticas corruptas maior será a eficiência do governo. Esses pontos gerais corroboram os resultados encontrados por Mignozetti (2011), Lopes e Toyoshima (2013) e Cruz e Ramos (2014), no que se refere ao impacto da corrupção sobre a eficiência do Estado em suas diversas modalidades de análise. 
No caso específico do Brasil, este trabalho mostra que, apesar de possuir um índice de controle de corrupção abaixo da média amostral (localizado na 17a posição no ranking de eficiência governamental), pode-se vislumbrar cenários mais promissores. A Operação Lava Jato, maior operação anticorrupção realizada no país até então, está provocando uma mudança nacional no tocante à tolerância com a corrupção, combatendo a histórica impunidade existente no sistema político e estatal brasileiro, desmantelando grandes esquemas de corrupção e investigando e penalizando inúmeros políticos, de diversas esferas do governo, e empresários brasileiros envolvidos nesses esquemas.

Vale salientar que os resultados encontrados pelas literaturas acadêmicas analisadas neste trabalho costumam recorrer aos pressupostos dados pelos artigos seminais ligados ao assunto, replicando-os às suas diversas realidades de análise. Além disso, quando se estuda o tema corrupção, as situações econômicas e políticas diferem entre grupos de países e regiões, tornando-se um fator deveras subjetivo, levando as análises propostas a realizarem associações de variáveis em seus modelos econométricos e não a efeitos de causalidades propriamente ditos, dado que cada contexto exige tratamento diferenciado. Não há uma fórmula fixa para definir e delinear a corrupção e seu efeito sobre a eficiência de um Estado.

Com base nos resultados estimados neste trabalho, recomenda-se, como políticas governamentais, o maior controle do processo de gestão da máquina pública, o fortalecimento das instituições fiscalizadoras de práticas corruptas, com independência comprovada em relação à administração central, além da redução do tamanho do Estado na economia, como meio de desburocratizar e inibir prováveis incentivos à corrupção. Por fim, a maior transparência das contas públicas, com rastreamento e controle de todo o processo de execução dos recursos aplicados à melhoria do bem-estar coletivo, poderia trazer maiores esclarecimentos às diversas classes da sociedade.

\section{REFERÊNCIAS}

ATLAS DO DESENVOLVIMENTO HUMANO NO BRASIL, 2010. Disponível em: http://atlasbrasil.org.br/2013/. Acesso em: abr. 2017.

BANCO MUNDIAL. Worldwide Governance Indicators. 2015. Available from: http://info.worldbank.org/ governance/wgi/\#home. Cited: May 2017.

CEPALSTAT. Perfiles nacionales. 2015. Disponible en: http://estadisticas.cepal.org/cepalstat/PerfilesNacionales.html?idioma=spanish. Acceso en: mayo 2017.

CRUZ, K. E. A.; RAMOS, F. S. Análise do impacto de variáveis socioeconômicas e de políticas coercitivas sobre a decisão do indivíduo em praticar atitudes criminosas. RDE - Revista de Desenvolvimento Econômico, v. 29, p. 150-159, 2014.

GUJARATI, D. N.; PORTER, D. C. Econometria básica. 5. ed. Porto Alegre: Amgh Editora, 2011.

LOPES, L. S.; TOYOSHIMA, S. H. Evidências do impacto da corrupção sobre a eficiência das políticas de saúde e educação nos Estados brasileiros. Planejamento e Políticas Públicas, n. 41, 2013.

MIGNOZZETTI, U. G. O impacto da corrupção sobre a qualidade do governo democrático. Plural, Revista do Programa de Pós-Graduação em Sociologia da USP, São Paulo, v. 18, n. 2, p. 111-133, 2011.

MOREIRA, J. M.; TELES, F. Bom governo: incentivos e seleção em política. CONGRESO NACIONAL DE ÉTICA DE LA ECONOMÍA Y DE LAS ORGANIZACIONES, 15., El Buen Gobierno de las Organizaciones. Barcelona: lese Business School, 2007. 
ONU. Organização das Nações Unidas. Human Development Report, 2016. Available from: http://hdr. undp.org/sites/default/files/2016_human_development_report.pdf. Cited: May 2017.

TANZI, V. Corrupção, atividades governamentais e mercados. Finanças e Desenvolvimento, v. 15, n. 4, 1995.

WOOLDRIDGE, J. M. Introdução à econometria: uma abordagem moderna. Tradução da quarta edição norte-americana. Boston: Editora Cengage Learning, 2006. 